Çukurova Üniversitesi Mühendislik Mimarlık Fakültesi Dergisi, 31(ÖS 2), ss. ÖS 33-ÖS 42, Ekim 2016

\title{
Asenkron Motorların Online Adaptif Sinirsel-Bulanık Denetim (ANFIS) Sistemine Dayalı Hız Denetim Performansının İncelenmesi
}

\author{
Sami ŞIT ${ }^{* 1}$, Hasan Rıza ÖZÇALIK ${ }^{1}$, Erdal KILIÇ², Osman DOĞMUŞ³ \\ Mahmut ALTUN ${ }^{1}$ \\ ${ }^{1}$ Kahramanmaraş Sütçü Imam Üniversitesi, Mühendislik Mimarlık Fakültesi, \\ Elektrik-Elektronik Mühendisliği Bölümü, Kahramanmaraş \\ ${ }^{2}$ Kahramanmaraş Sütçü İmam Üniversitesi, Afşin MYO, Elektrik ve Enerji Bölümü, \\ Kahramanmaraş \\ ${ }^{3}$ Kahramanmaraş Sütçü İmam Üniversitesi, Kahramanmaraş MYO, Elektronik Teknolojileri \\ Bölümü, Kahramanmaraş
}

Geliş tarihi: 01.09.2016 Kabul tarihi: 10.10 .2016

$\ddot{\mathbf{O z}}$

Üç fazlı asenkron motorların hız denetiminde sistemin doğrusal olmayan yapısı, yük momentindeki değişimler, parametre değişimleri ve bilinmeyen bozucu etkilerinden dolayı geleneksel PI tipi denetim ile iyi bir performans sağlanamamaktadır. Bu nedenle asenkron motorun hız denetiminde, daha iyi bir performans elde etmek için adaptif kontrol yöntemleri uygulanmaya başlamıştır. Bu çalışmada vektör kontrollü asenkron motorun hiz denetiminde geleneksel PI denetim yerine modern denetim yöntemlerinden olan adaptif sinirsel-bulanık denetim (ANFIS) sistemi önerilmiştir. Bu çalışmanın esas amacı, PI denetimli çalş̧madan elde edilen giriş-çıkış verileri kullanılarak önerilen denetleyici parametrelerini ayarlamak ve asenkron motorun hız denetiminde yüksek performans elde etmektir. Her iki denetim sisteminin performansı MATLAB/Simulink ortamında farklı çalışma koşullarında incelenmiş̧ir. Asenkron motorun hız kontrolü simülasyon çalışmasında, yükselme zamanı, aşım, yerleşme zamanı ve sürekli hal hatası gibi performans parametreleri ayarlanarak önerilen denetim sistemi geleneksel PI denetime kıyasla daha iyi bir performans sağlamıştır.

Ayrıca, sistemde referans hızın değiştirildiği ve yükün değiştirildiği bölgelerde ANFIS, geleneksel PI tipi denetimden daha iyi bir performansa sahip olduğu simülasyon sonuçlarından gözlemlenmiştir.

Anahtar Kelimeler: Asenkron motor, Adaptif sinirsel-bulanık denetim (ANFIS), PI denetim, Yapay sinir ağları

\section{Investigation of Performance Based on Online Adaptive Neuro-Fuzzy Inference System (ANFIS) for Speed Control of Induction Motors}

\begin{abstract}
In the speed control of three-phase induction motor, conventional PI type control can not provide a good performance due to non-linear structure of the system, change in load torque, change in parameters and
\end{abstract}

*Corresponding author (Sorumlu yazar): Sami Şi̇T, samisit@hotmail.com 
unknown disturbance effects. Therefore, adaptive control methods have been applied in speed control of induction motor in order to obtain better performance. In this study of speed control of vector controlled induction motor, adaptive neuro-fuzzy inference system (ANFIS) which is one of modern control techniques are commonly proposed compared to conventional PI control. The aim of the study is to set the parameters of proposed controller and to obtain high performance in speed control of induction motor by using obtained input-output data over PI control. The performance of both the control systems in MATLAB/Simulink environment was investigated in case of different operating conditions. In this simulation study of speed control of induction motor, the suggested controller produces better performance compared with the conventional PI controller by arranging the performance parameters such as rise time, overshoot, settling time and steady state error. Besides, it is observed that in the region of change in reference speed and change in load, ANFIS provided better performance than PI type control.

Keywords: Induction motor, Adaptive neuro-fuzzy inference system (ANFIS), PI control, Artificial neural networks

\section{GİRIȘ}

Asenkron motorların hız denetiminde, sistemin doğrusal olmayan yapısı, değişen çevre koşulları ve bozucu girişlerin etkisiyle iyi bir performans elde etmek oldukça zor olmaktadır. Son yıllarda elektronik cihaz teknolojisinde ve kontrol tekniklerindeki gelişmelerle birlikte doğru akım motorlarından elde edilebilen yüksek dinamik performans, asenkron motorlarda da elde edilmesi mümkün olmuştur. Asenkron motorlarda dolaylı alan yönlendirmeli vektör kontrolün kullanılmasıyla, DC motorlarda olduğu gibi, akı ve moment bileşenleri birbirinden bağımsız bir şekilde kontrol edilerek mükemmel bir dinamik performans sağlanmaktadır. Asenkron motor sürücülerinin performansının artırılmasında yapay zekâ tabanlı yöntemlerin kullanılmasının yararları son yıllardaki araştırmalarla açık bir şekilde ortaya konulmuştur [1-3]. Doğrusal olmayan sistemlerin tasarımlarında YSA (yapay sinir ağları)'nın doğrusal olmayan sistemleri modelleme yeteneğinden faydalanılmaktadır. YSA'nın öğrenme ve adaptasyon yeteneği kontrol sistemleri için ideal bir özelliktir. YSA yük parametreleri bilinmeyen bir motorun kontrolünde bile başarıyla uygulanabilmektedir. Bulanık mantık denetleyicinin yapısı uyarlanabilir özelliklere ve geniş çalışma koşullarına sahiptir. Ayrıca belirsizliklere, değişken parametrelere ve yük dağılımına sahip sistemlerin denetiminde kullanıldığında sistemin güçlü cevaplar vermesini sağlar [4-6].
Adaptif Sinirsel- Bulanık Çıkarım Sistemi, yapay sinir ağlarının paralel hesaplayabilme ve öğrenme kabiliyeti ile bulanık mantığın çıkarım özelliğini kullanan melez bir adaptif kontrol yöntemidir. ANFIS, daha iyi performans ve doğruluk sağlamak için tasarlanan modern kontrol sistemlerinde yaygın olarak kullanılan kontrol stratejilerden biridir [7-8]. Adaptif kontrolün amacı bilinmeyen veya değişen kontrol parametrelerini ayarlamaktır. Adaptif bulanık sistemlerin kullanılmasıyla gerçekleştirilen, modelleme ve denetim uygulamaları da literatürde geniş bir biçimde yer almaktadır. $\mathrm{Bu}$ nedenle bulanık sistemlerin etkinliğinin artırılmasında, uyarlama tekniğinin katkısını sağlamaya yönelik çeşitli yöntemler geliştirilmiştir. Bu çalışmada üç fazlı bir asenkron motorun hız denetimi için ANFIS denetleyici geliştirilmiştir. $\mathrm{Bu}$ çalışmamızda asenkron motorun hız hata ve hata değişimi parametreleri giriş çıkışları incelenmiştir ve asenkron motorun tepkisine ait ANFIS denetimi ve referans1 yakalama başarısı sergilenmiştir. ANFIS ve PI tipi klasik denetleyici kullanılarak asenkron motorun vektör esaslı hız denetiminin benzetim çalışması MATLAB/Simulink ortamında yapılmıştır. Çalışmada asenkron motorun sürme yönteminde alan yönlendirmeli vektör kontrol yöntemi kullanılmıştır [8]. Eviricinin anahtarlamasında Uzay Vektör Darbe Genişlik Modülasyonu (UVDGM) kullanılmıştır. ANFIS ve PI tipi denetleyici için asenkron motorun değişken referans ve yük altında gösterdikleri tepkileri incelenmiş ve benzetim sonuçları karşılaştırılmıştır. 


\section{MATERYAL VE METOT}

\subsection{Materyal}

Bir sistemin fiziksel davranışının benzetimini yapmak için, matematiksel modelinin çıkarılması gereklidir. Model üzerinde yapılan çalışmalarla sistemin kontrolü için en uygun kontrol kuralları belirlenebilmektedir. Asenkron motorun matematiksel modelini elde etmek için motora ait üç faz değişkenleri d-q düzlemine aktarılmaktadır. Böylece senkron hızda dönen $\mathrm{d}-\mathrm{q}$ eksen takımındaki modele alan yönlendirmeli kontrol uygulanarak asenkron motor bir doğru akım motoruna benzetilmektedir. $\mathrm{Bu}$ model, kontrol kuralları belirlemekte kullanılan bilgisayar analiz ve benzetim çalışmalarına uygun bir hale getirilmiştir [8-11]. Şekil 1'de asenkron motorun matematiksel modelini elde etmek için üç fazlı değişkenlerin d-q eksen takımına aktarımı gösterilmiştir.

Asenkron motor için $\mathrm{d}-\mathrm{q}$ eksen takımındaki diferansiyel denklemleri, denklem 1-9'deki gibi düzenlenebilir [11].

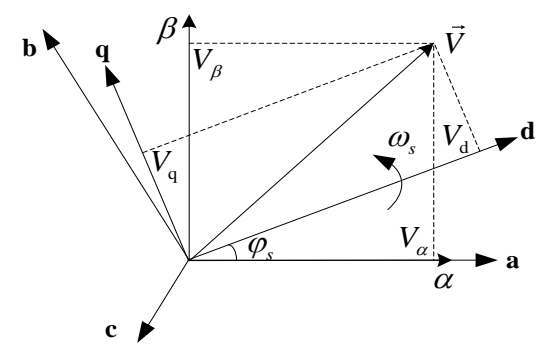

Şekil 1. a-b-c, $\alpha-\beta$ ve d-q eksen takımları düzlemi

Eşdeğer direnç;

$$
R_{E}=R_{s}+\frac{R_{r}^{\prime} L_{m}^{2}}{L_{r}^{\prime 2}}
$$

Kaçak faktörü;

$$
\sigma=1-\frac{L_{m}^{2}}{L_{s} L_{r}^{\prime 2}}
$$

$$
\begin{aligned}
& \frac{d i_{s d}}{d t}=\frac{1}{\sigma L_{s}}\left[-R_{E} i_{s d}+\sigma L_{s} \omega_{s} i_{s q}+\frac{L_{m} R_{r}^{\prime}}{L_{r}^{2}} \psi_{r d}+\omega_{r} \frac{L_{m}}{L_{r}^{\prime}} \psi_{r q}+V_{s d}\right] \\
& \frac{d i_{s q}}{d t}=\frac{1}{\sigma L_{s}}\left[-R_{E} i_{s q}-\sigma L_{s} \omega_{s} i_{s d}-\omega_{r} \frac{L_{m}}{L_{r}^{\prime}} \psi_{r d}+\frac{L_{m} R_{r}^{\prime}}{L_{r}^{\prime 2}} \psi_{r q}+V_{s q}\right] \\
& \frac{d \psi_{r d}}{d t}=\frac{R_{r}^{\prime} L_{m}}{L_{r}^{\prime}} i_{s d}-\frac{R_{r}^{\prime}}{L_{r}^{\prime}} \psi_{r d}+\omega_{s l} \psi_{r q} \\
& \frac{d \psi_{r q}}{d t}=\frac{R_{r}^{\prime} L_{m}}{L_{r}^{\prime}} i_{s q}-\frac{R_{r}^{\prime}}{L_{r}^{\prime}} \psi_{r q}-\omega_{s l} \psi_{r d} \\
& \frac{d \omega_{m}}{d t}=\frac{p L_{m}}{J L_{r}^{\prime}}\left(i_{s q} \psi_{r d}-\psi_{r q} i_{s d}\right)-\frac{B}{J} \omega_{m}
\end{aligned}
$$

Kayma hız1;

$$
\omega_{s l}=\omega_{s}-\omega_{r}=\frac{R_{r}^{\prime} i_{q s}}{L_{r}^{\prime} i_{d s}}
$$

Senkron pozisyon;

$$
\theta_{S}=\int \omega_{S} d t
$$

$\omega_{s}$ ve $\omega_{r}$ sirayla elektriksel senkron hizı ve rotor hızını belirtmektedir; $V_{s d}, V_{s q}, \quad i_{s d}, i_{s q}, \psi_{r d}$ ve $\psi_{r q}$ parametreleri ise sirasiyla d-q ekseni stator gerilimleri, d-q ekseni stator akımlarını ve d-q ekseni rotor akılarını ifade etmektedir. $R_{s}$ ve $R_{r}$ ise her faz için stator ve rotor dirençlerini gösteriyor; Yine aynı şekilde $L_{s}, L_{r}$ ve $L_{m}$ stator ve rotorun ana indüktanslarını ve karşılıklı indüktanslarını; $p$ motor kutup sayısını, $J$ rotor ataletini, $B$ viskoz sürtünme katsayısını, $T_{L}$ yük momentini, $R_{E}$ eşdeğer direnci, $\sigma$ ise kaçak faktör katsayısını ifade etmektedir.

\subsection{Metot}

ANFIS temel olarak Bulanık Çıkarım Sistemi'nin (Fuzzy Inference System) adaptif sinirsel ağlara uyarlanmış halidir. Melez öğrenme algoritması ile birlikte ANFIS, bulanık eğer-ise kuralları ile insan bilgisini yansıtan girdi çıktı yapısını ortaya 
koymaktadır. 1993 yıllında R. Jang tarafindan ANFIS yöntemini geliştirmiş ve doğrusal olmayan fonksiyonların modellenmesinde, kaotik zaman serilerinin tahmininde kullanmıştır [7]. MATLAB yazılımındaki bulanık mantık modülünde bir kullanıcı ara yüzü (ANFIS Editor) aracılığı ile yöntem araştırmacıların kullanımına sunulmuştur. Yöntemin çıkış noktası, insan düşünce ve bilgisini yansıtan bulanık Ĕger-ise kurallarının avantajı ile sinirsel ağların öğrenme yeteneklerini bir araya getirerek entegre etkili bir çözüm sunma gereksinimidir.

Bulanık eğer-ise kuralları, "Eğer A koşul ise B sonuçtur." şeklinde ifade edilebilecek kurallar olup bulanık çıkarım sistemlerinin de temelini oluşturmaktadır. Yapıları itibariyle, bulanık ve belirsiz ortamlarda insan düşünce ve muhakeme yeteneğini yansitma kabiliyeti bulunmaktadır. Bulanık çıkarım sistemi de bulanık eğer-ise kurallarını kullanarak ve kati sayısal analizleri kullanmadan insan bilgisinin muhakeme sürecini ve nicel yönünü modelleyebilmektedir.

Adaptif sinirsel ağ, çeşitli sayıda birbirine bağlanmış düğümler içeren, elde bulunan girdi ve çıktı veri setini ortaya koymaya yarayan bir ağ yapısıdır. Her bir düğüm bir işlem birimi içerir ve düğümler arası bağlantılar, birleştirilen düğümler arasındaki nedensel ilişkiyi belirler [11]. Düğümlerin hepsi veya bir kısmı adaptiftir, bunun anlamı dügüumlerin çıktısının bu dügüumlerle ilişkili düzenlenebilir parametrelere dayandığıdır. Öğrenme kuralı, öngörülmüş bir hata ölçüsünü minimize etme adına bu parametrelerin nasıl güncellenmesi gerektiğini belirler. Hata ölçüsü ağın mevcut çıktısı ile beklenen çıktı arasındaki farkı belirten matematiksel bir gösterimdir. ANFIS'in en önemli özelliği gradyan azaltım (gradient descent) ve en küçük kareler yöntemini bir arada uygulayarak sunduğu melez öğrenme algoritmasıdır ve bu da ANFIS'in diğer yöntemlere yönelik üstünlüğünde temel teşkil etmektedir. Şekil 2'de iki kurallı ve iki girdili birinci derece Sugeno bulanık modeli ile buna karşılık gelen ANFIS yapısı yer almaktadır. Düğümlerin 4. Katmana kadar ileri gidişlerinde soncul parametreler en küçük kareler yöntemi ile belirlenmekte, geriye doğru gidişte ise bu sefer öncül parametreler gradyan azaltım yöntemi ile belirlenmektedir [7-8]

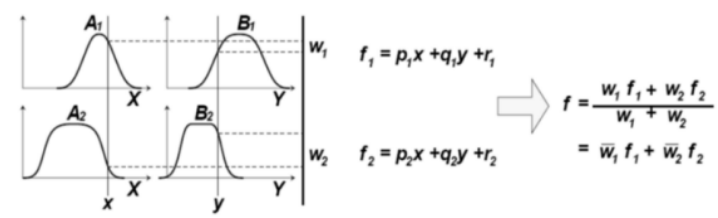

a)

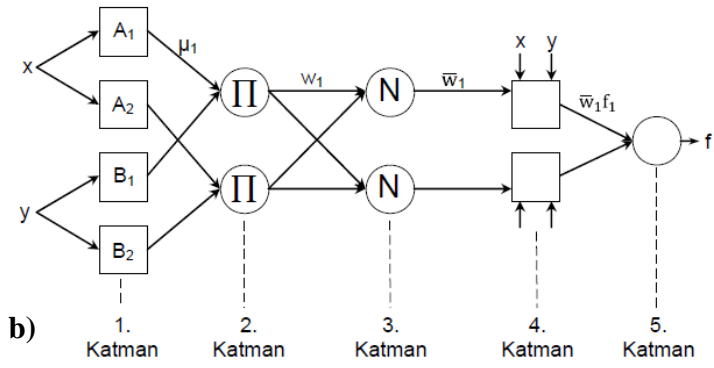

Şekil 2. (a) Sugeno bulanık modeli, (b) ANFIS yapis1 [12-13]

Şekil 2'de belirtildiği üzere ANFIS beş katmandan oluşmaktadır. Her bir katmanın fonksiyonları aşağıda anlatılmaktadır.

ANFIS'ın giriş değişkenleri olan $\mathrm{x}=e(\mathrm{t})$ hatayı ve $\mathrm{y}=\Delta e(\mathrm{t})$ ise hata değişimi ifade eder.

Katman 1: Bu katmanda her düğüm kare olup bir düğüm fonksiyonu ile ilişkilidir.

$O_{i}^{1}=\mu_{A_{i}}(x)$

x i düğümü ile ilişkili girdi, $A_{i}$ ise ilgili düğüm fonksiyonu ile ilişkili sözel değişkendir (iyi, çok iyi vs.). Diğer bir ifadeyle, $O_{i}^{1}, A i$ 'nin üyelik fonksiyonu olup x'in A'yı ne kadar karşıladığının derecesini vermektedir. Genel olarak, $\mu_{A i}(x)$ maksimum 1 ve minimum 0'a eşit olmak üzere çan eğrisi şeklinde seçilir:

$$
O_{i}^{1}=\mu_{A_{i}}(x)=\frac{1}{1+\left[\left(\frac{x-c_{i}}{a_{i}}\right)^{2}\right]^{b_{i}}}
$$

veya 
$\mu_{A_{i}}(x)=\exp \left\{-\left(\frac{x-c_{i}}{a_{i}}\right)^{2}\right\}$

$\left\{a_{i}, b_{i}, c_{i}\right\}$ parametre seti olup öncül parametreler olarak nitelendirilir. Bu aşamada çeşitli üyelik fonksiyonları kullanılabilmektedir.

Katman 2: Bu katmanda yer alan bütün düğümler (П) daire şeklinde olup gelen sinyalleri çarpıp değeri dışarı çıkarır.

$O_{i}^{2}=w_{i}=\mu_{A_{i}}(x) \mu_{B_{i}}(y)$

Her düğüm çıktısı, her bir kuralın ateşleme seviyesini (firing strength) gösterir.

Katman 3: Bu katmanda yer alan bütün düğümler $(N)$ daire şeklinde olup, $i$. düğüm, $i$. kuralın ateşleme seviyesinin tüm kuralların toplam ateşleme seviyesine oranını hesaplar.

$O_{i}^{3}=\overline{w_{i}}=\frac{w_{i}}{\sum_{i} w_{i}}, i=1,2 \ldots$

$\mathrm{Bu}$ katmanın çıktısı normalleştirilmiş ateşleme seviyesi olarak da nitelendirilmektedir.

Katman 4: Bu katmanda her düğüm kare olup bir düğüm fonksiyonu ile ilişkilidir.

$O_{i}^{4}=\overline{w_{i}} f_{i}=\bar{w}_{i}\left(p_{i} x+q_{i} y+r_{i}\right) \rightarrow i=1,2 \ldots$

$w_{i}$ katman 3'ün çıktısı olup normalleştirilmiş tetikleme seviyesidir. $\left\{p_{i}, q_{i}, r_{i}\right\}$ ayarlanabilmesi için gerekli olan, ayar değişken kümesidir. Bu katmandaki değişkenler sonuç değişkenlere karşılık gelir.

Katman 5: Bu katmanda yer alan tek düğüm $(\Sigma)$ daire şeklinde olup tüm çıkışları bütün gelen sinyallerin toplamı şeklinde hesaplar. Burada elde edilen sonuç sistemin gerçek çıkışı $f$ değerini verir.
Ağın gerçek çıkışı ise aşağıdaki eşitlikte verilmiştir [14].

$O_{i}^{5}=\sum_{i} \overline{w_{i}} f_{i}=\frac{\sum_{i} w_{i} f_{i}}{\sum_{i} w_{i}}$

ANFIS parametreleri aşağıdaki gibi hata teriminin geri yayılım algoritması kullanarak güncellenir:

$\frac{\partial E}{\partial O^{5}}=k_{1} \cdot e+k_{2} \cdot \Delta e$

Giriş sinyalleri hata $(e)$ ve hatanın değişimi $(\Delta e) \mathrm{k}_{1}$ ve $\mathrm{k}_{2}$ katsayıları ile çarpılır.

$\alpha_{k+1}=\alpha_{k}-\eta \frac{\partial E}{\partial \alpha_{k}}$

Burada $\alpha$ ANFIS',n herhangi bir parametresi ve $\eta$ öğrenme oranıdır. Hata sonraki eğitim iterasyonu azaltacaktır [8].

\section{BULGULAR}

Asenkron motorun hız denetimine ait simülasyon çalışmalarında MATLAB/Simulink programı kullanılmıştır. Çalışmada kullanılan asenkron motora ait parametreler Çizelge 1'de verilmiştir.

Çizelge 1. Asenkron motor parametreleri

\begin{tabular}{|l|c|c|c|}
\hline Parametreler & Simge & Birim & Değeri \\
\hline Nominal güç & $\mathrm{P}$ & $\mathrm{kW}$ & 3 \\
\hline Nominal hız & $\mathrm{n}$ & $\mathrm{dev} / \mathrm{dk}$ & 1430 \\
\hline Nominal stator gerilimi & $\mathrm{U}$ & $\mathrm{V}$ & 380 \\
\hline Nominal stator akımı & $\mathrm{I}$ & $\mathrm{A}$ & 6,7 \\
\hline Stator direnci & $\mathrm{R}_{\mathrm{s}}$ & $\Omega$ & 1,45 \\
\hline Rotor direnci & $\mathrm{R}_{\mathrm{r}}$ & $\Omega$ & 1,93 \\
\hline Moment & $\mathrm{M}$ & $\mathrm{Nm}$ & 19 \\
\hline Hava aralığı endüktans1 & $\mathrm{L}_{\mathrm{m}}$ & $\mathrm{H}$ & 0,1878 \\
\hline Eylemsizlik momenti & $\mathrm{J}$ & $\mathrm{Kg} . \mathrm{m}^{2}$ & 0,03 \\
\hline Sürtünme momenti & $\mathrm{B}$ & $\mathrm{Nm} . \mathrm{s} / \mathrm{rd}$ & 0,03 \\
\hline Kutup çifti sayıs1 & $\mathrm{p}$ & & 2 \\
\hline
\end{tabular}


Motor çıkışından alınan değerler ile referans hız ve akı bilgileri karşılaştırılarak hata değerleri elde edilmiştir. $\mathrm{Bu}$ değerler kullanılarak modülasyon için gerekli dönüşümler ve hesaplamalar yapılmıştır. Referans gerilim vektörünün bulunduğu sektöre göre eviricinin uygun anahtarlama vektörleri tespiti yapılmıştır. $\mathrm{Bu}$ vektörlerin süreleri hesaplanarak elde edilen
UVDGM sinyalleri eviriciye uygulanarak motor sürülmüştür. Bu çalışmada kontrolör çıkışında elde edilen sayısal değerler $V_{d}$ ve $V_{q}$ gerilimleridir.

Çalışmada kullanılan eviricinin besleme gerilimi $450 \mathrm{~V}_{\mathrm{DC}}$ olup anahtarlama frekans1 $5 \mathrm{kHz}$ tir. Çalışmada örnekleme zamanı $T_{S}=0,2 \mathrm{~ms}$ olarak alınmıştır.

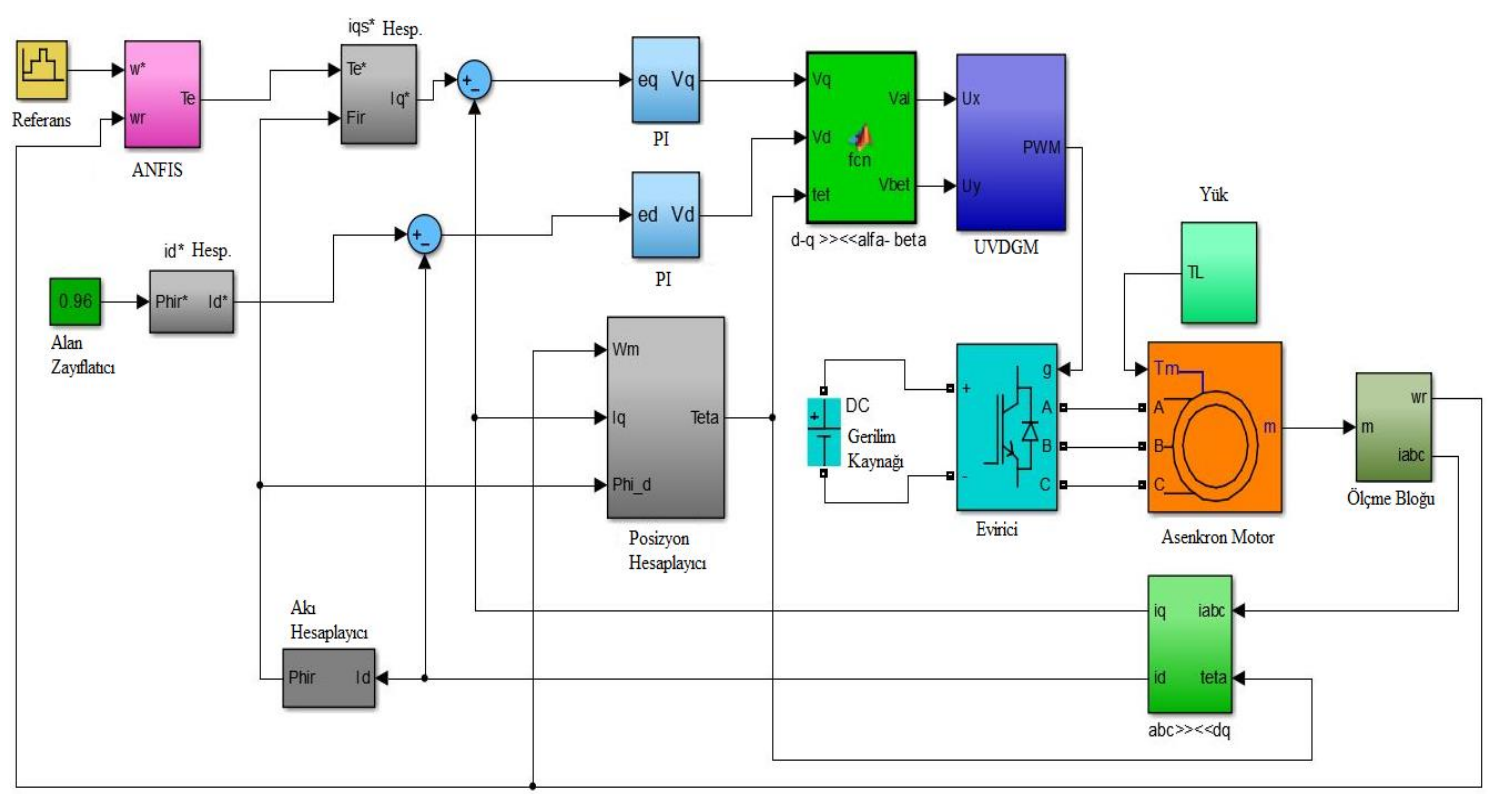

Şekil 3. Vektör kontrollü asenkron motor sürücü sistemine ait Simulink model

Asenkron motorun simülasyon çalışmasında referans hız değeri $\mathrm{t}=0-0,5$ saniye için $1000, \mathrm{t}=0,5$ 1,5 saniye aras 1400 ve $t=1,5-2$ saniye arasinda ise $800 \mathrm{dev} / \mathrm{dk}$ olarak verilmiştir. Asenkron motor yüksüz çalıştırılmıştır. Elde edilen PI tipi ve ANFIS tipi denetimin değişen referans hız değerlerine ulaşma tepkileri Şekil 4'teki hız-zaman grafiğinde gösterilmiştir.

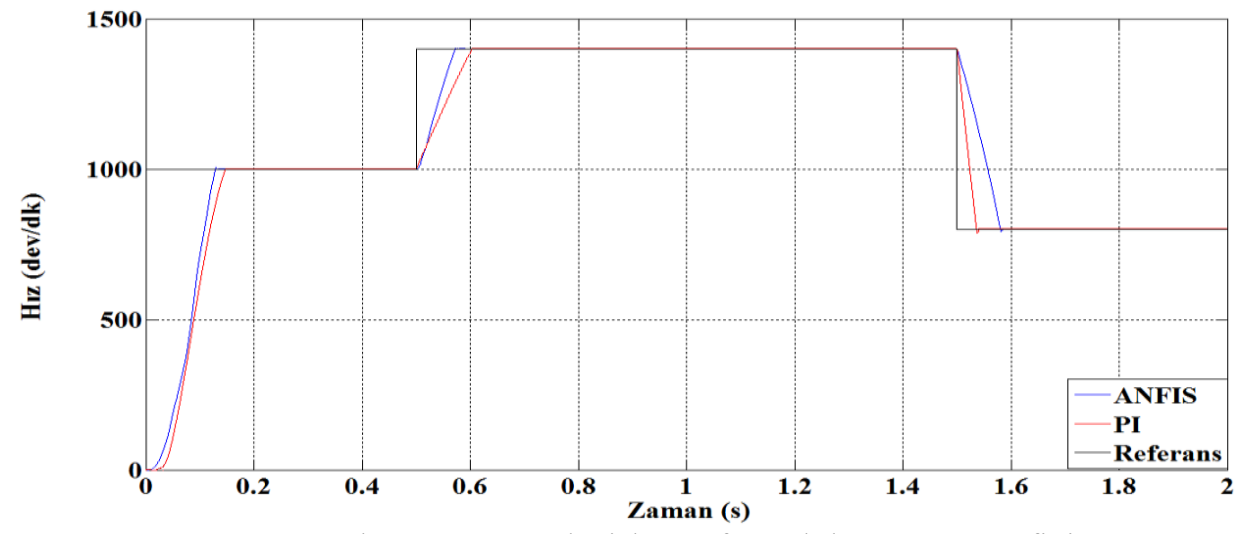

Şekil 4. Asenkron motorun değişken referanslı hız-zaman grafiği 
Asenkron motorun simülasyon çalışmasında değişken referanslı hız değeri, $\mathrm{t}=0-0,5$ saniye için $1000, t=0,5-1,5$ saniye aras 1400 ve $t=1,5-2$ saniye arasında ise $800 \mathrm{dev} / \mathrm{dk}$ olarak verilmiştir. Çalışmanın 1'inci saniyesinde motora $19 \mathrm{Nm}$ yük uygulanmıştır. Geleneksel PI tipi ve ANFIS tipi denetimin değişen referans hız değerlerine ulaşma ve yüklenme durumundaki tepkileri Şekil 5'teki hız-zaman grafiğinde gösterilmiştir.

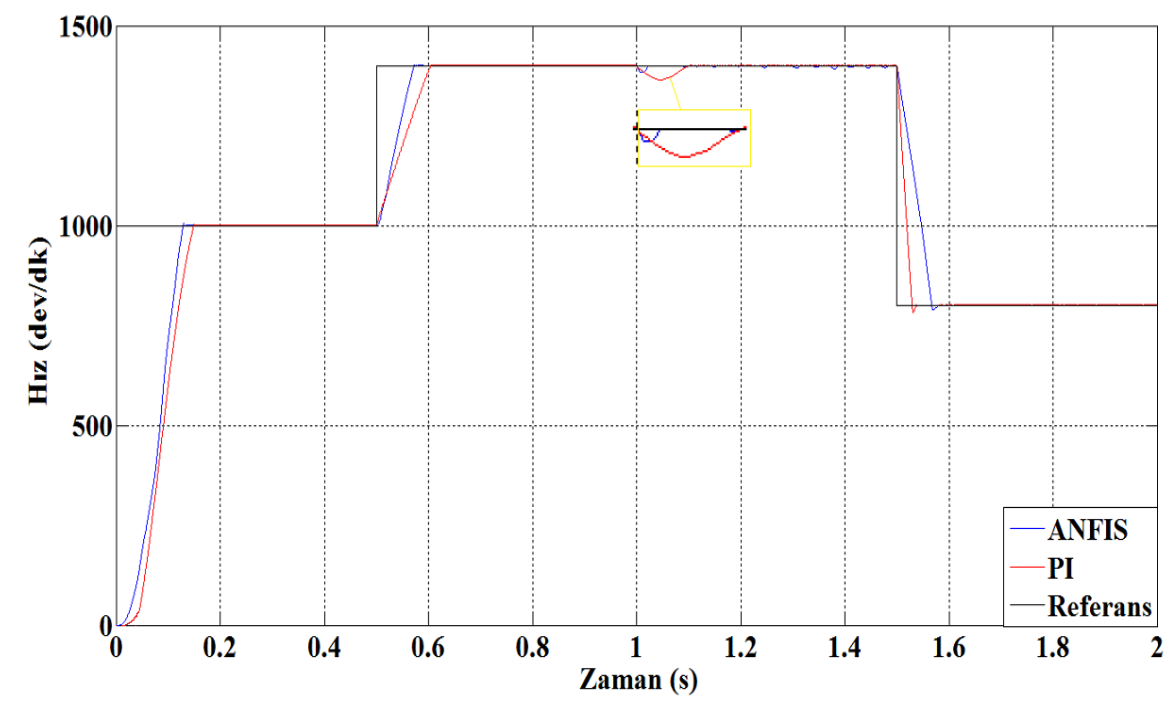

Şekil 5. Yüklenme anında asenkron motorun değişken referanslı hız-zaman grafiğ

Asenkron motorun simülasyon çalışmasında değişken referanslı hız değeri, $\mathrm{t}=0-0,5$ saniye için $1000, \mathrm{t}=0,5-1,5$ saniye aras 1400 ve $\mathrm{t}=1,5-2$ saniye arasında ise $800 \mathrm{dev} / \mathrm{dk}$ olarak verilmiştir.
Çalışmanın 1'inci saniyesinde motora $19 \mathrm{Nm}$ yük uygulanmıştır. ANFIS tipi ve PI tipi denetimin değişen referans hiz değerlerine ait moment değişimleri Şekil 6'daki grafikte gösterilmiştir.

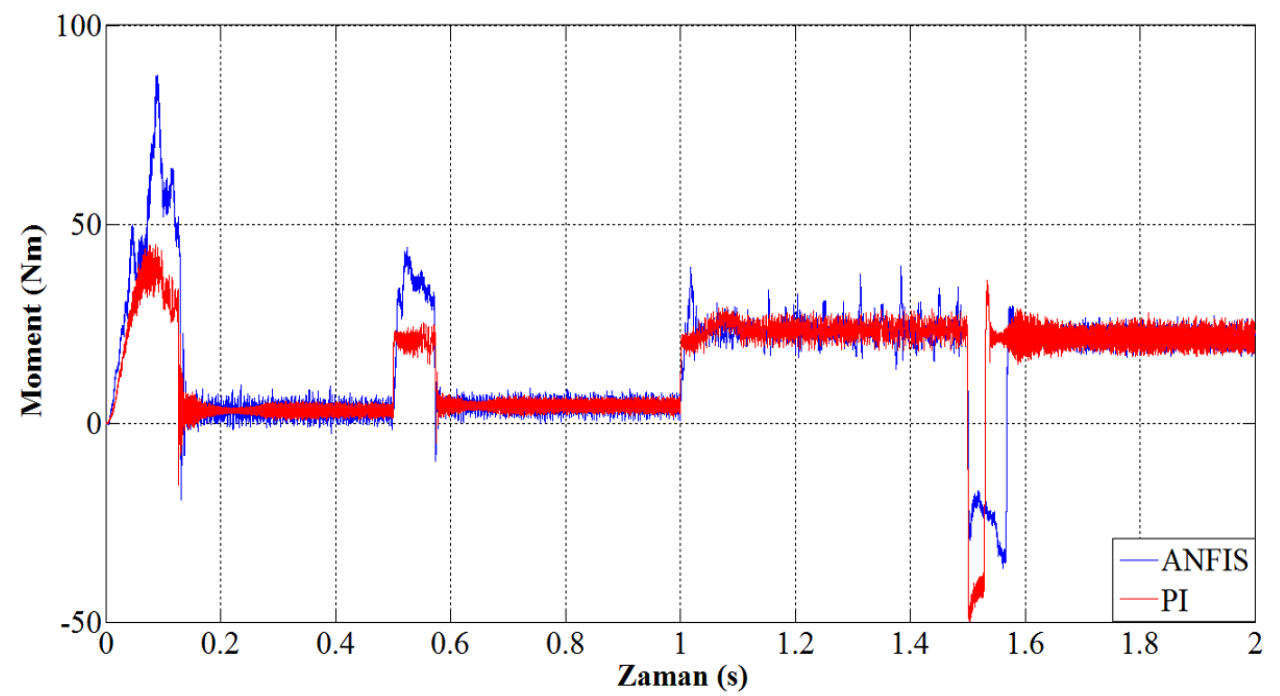

Şekil 6. Asenkron motorun moment-zaman grafiği 


\section{SONUÇ}

$\mathrm{Bu}$ çalışmada ANFIS ve PI tipi denetleyici için asenkron motorun değişken referans ve yük altında gösterdikleri tepkileri incelenmiş ve benzetim sonuçları karşılaştırılmıştır. Her iki denetim sisteminin performansı MATLAB/Simulink ortamında farklı çalışma koşullarında incelenmiştir.

Simülasyon çalışmasında, asenkron motorun hız kontrolü, yükselme zamanı, aşım, yerleşme zamanı ve sürekli hal hatası gibi performans parametreleri ayarlanarak ANFIS tipi denetim geleneksel PI denetime kıyasla daha iyi bir performans sağlamıştır. Ayrıca, sistemde referans hızın değiştirildiği ve yüklenme yapıldıktan sonra ANFIS tipi denetleyici, geleneksel PI tipi denetimden daha iyi bir performansa sahip olduğu simülasyon sonuçlarından gözlemlenmiştir.

Üç fazlı asenkron motorlar gibi doğrusal olmayan sistemeler için ANFIS tipi denetleyiciler önerilebilir.

\section{KAYNAKLAR}

1. Sit, S., Kilic, E., Ozcalik, H.R., Altun, M., Gani, A., 2016. Model Reference Adaptive Control based on RBFNN for Speed Control of Induction Motors, International Conference on Natural Science and Engineering (ICNASE'16), pp. 3355-3364.

2. Kim, G-S., Ha, I-J., Myoung-Sam KO., 1992. Control of Induction Motors for Both High Dynamic Performance and High Power Efficiency, IEEE Transactions on Industrial Electronics, Vol. 39, No. 4, August 1992.

3. Sit, S., Ozcalik, H.R., Kilic, E., Yilmaz, S., 2015. Investigation of Speed Control Method in Three-Phase Induction Motor Drives, International Refereed Journal of Engineering and Sciences, Vol:2 No:5, pp. 125-151 (Open Access, DRJI, ISRA).

4. Eltamaly, A.M., Alolah, A.I., Badr, B.M., 2010. Fuzzy Controller for Three Phases Induction Motor Drives, IEEE Autonomous and Intelligent Systems-First International
Conference, (AIS 2010), Povoa de Varzim, Portugal, June 21-23.

5. Fu, X., Li, S., 2015. A Novel Neural Network Vector Control Technique for Induction Motor Drive, IEEE Transactions on Energy Conversion, Vol. 30, No. 4, December 2015. pp. 1428-1437.

6. Niasar, A.H., Khoei, H.K., 2015. Sensorless Direct Power Control of Induction Motor Drive Using Artificial Neural Network, Hindawi Publishing Corporation Advances in Artificial Neural Systems, Volume 2015, Article ID 318589 , p. 9.

7. Jang, J.S.R., 1993. ANFIS: Adaptive-NetworkBased Fuzzy Inference System, IEEE Transactions on Systems, Man, and Cybernetics, Vol. 23, No. 3, pp. 665-685. http://dx.doi.org/10.1109/21.256541

8. Kilic, E., Ozcalik, H.R., Yilmaz, S., Sit, S., 2015. A Comparative Analysis of FLC and ANFIS Controller for Vector Controlled Induction Motor Drive, 2015 IEEE International Aegean Conference on Electrical Machines \& Power Electronics (ACEMP2015), 2-4 September 2015, Side-Antalya, Turkey.

9. Özçalık, H.R., Kılıç, E., Şit, S., 2013. Uzay Vektör Darbe Genişlik Modülasyonu İle Sürülen Üç Fazlı Bir Asenkron Motorun Denetiminde PI-Fuzzy Tipi Denetim Yönteminin Başarımının İncelenmesi, 15. Otomatik Kontrol Ulusal Toplantıs1, TOK2013, Malatya, Türkiye, ss:1153-1158, 26-28.

10. Paçacı, S., 2011. Yapay Sinir Ağları, Bulanık Mantık ve Sinirsel Bulanık Denetleyiciler ile Asenkron Motorların Hiz Denetimi için Simülatör Tasarımı, Süleyman Demirel Üniversitesi, Fen Bilimleri Enstitüsü, Yüksek Lisans Tezi, Isparta.

11. Şit, S., 2013. Üç Fazlı Sincap Kafesli İndüksiyon Motorunun Bulanık Mantık Esaslı Yöntemler Kullanılarak Denetimi. Yüksek Lisans Tezi, KSÜ, Fen Bilimleri Enstitüsü, Kahramanmaraş, 87.

12. Sugeno, M., Takagi, T., 1985. Fuzzy Identification of Systems and its Applications to Modelling and Control, IEEE Transactions on Systems, Man, and Cybernetics, Vol. 15, pp. 116-132. 
13. Tutmez, B., Hatipoglu, Z., Kaymak, U., 2006. Modelling Electrical Conductivity of groundwater using an Adaptive Neuro-Fuzzy Inference System. Computer \& Geosciences 32 (4), 421-433.

14. Elmas, Ç., 2011. Yapay Zeka Uygulamaları, Seçkin Yayıncılık, Ankara. 
